\title{
Tissue-specific GHR knockout mice: metabolic phenotypes
}

\author{
Liou Y. Sun and Andrzej Bartke* \\ Department of Internal Medicine, Southern Illinois University School of Medicine, Springfield, IL, USA
}

\author{
Edited by: \\ Hugo Aguilaniu, Centre National de la \\ Recherche Scientifique, France \\ Reviewed by: \\ Rosemary O'Connor, University \\ College Cork, Ireland \\ Joseph Baur, Perelman School of \\ Medicine at the University of \\ Pennsylvania, USA \\ Marc Tatar, Brown University, USA \\ ${ }^{*}$ Correspondence: \\ Andrzej Bartke, Department of \\ Internal Medicine, Southern Illinois \\ University School of Medicine, $801 \mathrm{~N}$. \\ Rutledge, Room 4389, P.O. Box \\ 19628, Springfield, IL 62794-9628, \\ USA \\ e-mail: abartke@siumed.edu
}

In addition to its major role in the regulation of somatic growth, growth hormone (GH) signaling has profound effects on function of various tissues in the body. However, the cellular location where the $\mathrm{GH}$ signaling exerts its effect on metabolic homeostasis remains largely unknown. Here, we briefly review recent progress and insights from mice with $\mathrm{GH}$ receptor deletion specifically in adipocytes, macrophages, hepatocytes, pancreatic $\beta$-cells, and skeletal muscle cell types. These studies have greatly enhanced our understanding of the GH-IGF-I physiological function.

\section{Keywords: GH signaling, mice, GHRKO, hepatic GHR signaling, adipocytes, macrophages}

\section{INTRODUCTION}

In addition to its major role in the regulation of somatic growth (1), growth hormone $(\mathrm{GH})$ is a major regulator of gene expression and protein synthesis in the liver, fat mobilization in the metabolically active tissues, and organ response to insulin (1). Hepatocytes, pancreatic beta cells, adipocytes, macrophages, and muscle cells are among the cell types that express GH receptors and are critical targets for $\mathrm{GH}$ action. Effects of $\mathrm{GH}$ on these cells are thought to be predominantly direct, whereas many of its effects are mediated through circulating insulin-like growth factor I (IGF-I) or local (auto/paracrine) IGF-I actions. In 1997, the Kopchick laboratory reported creating mice with targeted deletion ("knockout") of the GH receptor and they resulting profound GH resistance, reduction of circulating IGF-I levels, disruption of the negative IGF-I feedback, and increase in plasma levels of $\mathrm{GH}$ (2). Studies of these animals provided much new information about physiological actions in mammals (3). Mice homozygous for GHR deletion (GHR-KO mice) have markedly increased adiposity and yet are metabolically "healthy" with reduced levels of insulin, reduced or normal levels of glucose, enhanced insulin sensitivity, increased adiponectin levels, reduced blood pressure, and significantly extended longevity of both females and males (3). The fascinating consequences of the global deletion of $\mathrm{GH}$ receptors in GHR-KO mice stimulated interest in identifying the role of GH signaling in different target organs of this hormone. It is believed that GH exerts systemic effects primarily through liver-derived IGF-I and adipocyte-derived circulating proteins, such as adipokines and cytokines. Surprisingly, liver-specific IGF-I deletion in mice (LID) (4) has almost no effect on postnatal somatic growth. Moreover, LID mice were found to have hyperinsulinemia and muscle insulin resistance (5). Insulin resistance of these animals was ascribed to stimulation of GH release in response to reduced levels of IGF-I in the circulation. In support of this interpretation suppressing $\mathrm{GH}$ level by GH-releasing hormone antagonist dramatically increased insulin sensitivity in these mice (5). These data suggest that GH plays a direct role in systemic carbohydrate metabolism, glucose homeostasis, and insulin action. However, the cellular location of the GH actions remains largely unknown. In this article, we will briefly review the results of studies aimed at identifying the role of different organs or cell types in mediating the physiological effects of GH.

\section{TISSUE-SPECIFIC GHR SIGNALING}

Utilizing the Cre/LoxP system, recent studies of mice with GH receptor deletion specifically in various cell types have greatly enhanced our understanding of the GH-IGF-I axis. Results obtained in these animals provide novel insights into the critical role of the local GH signaling in the particular tissues. Published evidence indicated that each of these organ-specific GHRKO mice has its own unique set of physiological and metabolic features. Some of the findings are consistent with the results obtained in the whole-body GHR null mice, while others are seen only in specific organ GHRKO mutants, suggesting that the existence of previously unknown interactions between GH target tissues. The most important phenotypical changes in mice with organ-specific disruption of GHR signaling are summarized in Table $\mathbf{1}$ and Figure $\mathbf{1}$ and are discussed below.

\section{GHR SIGNALING DISRUPTION IN ADIPOCYTES AND MACROPHAGES}

Growth hormone exerts profound effects on adipose tissue. Overall, GH regulates adipocyte proliferation and differentiation and decreases fat deposition by both inhibiting triglyceride accumulation and increasing lipolysis. Furthermore, GH has been shown to negatively regulate the secretion of adipokines such as leptin and adiponectin. Compared to littermate control mice, the whole-body GHR null mice have higher percent body fat with elevated circulating adiponectin and leptin levels. Intriguingly, 
Table 1 | Major phenotypical and metabolic changes in mice with organ-specific disruption of GHR signaling

\begin{tabular}{|c|c|c|c|c|c|c|c|c|c|c|}
\hline Name & Tissue & Cre & $\begin{array}{l}\text { Life } \\
\text { Span }\end{array}$ & Strain & Obesity & $\begin{array}{l}\text { Blood } \\
\text { GH }\end{array}$ & $\begin{array}{l}\text { Blood } \\
\text { IGF-I }\end{array}$ & $\begin{array}{l}\text { Insulin } \\
\text { sensitivity }\end{array}$ & $\begin{array}{l}\text { Glucose } \\
\text { tolerance }\end{array}$ & Other metabolic changes \\
\hline GHRKO & Whole-body & & $\uparrow$ & Ola-BALB/c & $\uparrow$ & $\uparrow$ & $\downarrow$ & $\uparrow$ & $\uparrow$ & $\uparrow$ Adiponectin, leptin \\
\hline Fat-GHRKO & Adipocytes & $\mathrm{aP} 2$ & $?$ & C57BL/G & $\uparrow$ & N.C. & N.C. & N.C. & N.C. & \\
\hline $\begin{array}{l}\text { Mac- } \\
\text { GHRKO }\end{array}$ & Macrophages & LysM & $?$ & C57BL/6 & $\uparrow \mathrm{HFD}$ & & N.C. & $\downarrow \mathrm{HFD}$ & $\downarrow \mathrm{HFD}$ & $\begin{array}{l}\text { Metabolic normal fed with } \\
\text { normal chow }\end{array}$ \\
\hline Liv-GHRKO & Hepatocytes & Albumin & $?$ & C57BL/6 & N.C. & $\uparrow$ & $\downarrow$ & N.C. & N.C. & $\begin{array}{l}\text { Fatty liver phenotype only in } \\
\text { male (7) }\end{array}$ \\
\hline$\beta$-GHRKO & $\begin{array}{l}\text { Pancreatic } \\
\beta \text {-cells }\end{array}$ & Rip & $?$ & C57BL/6 & N.C. & & N.C. & $\downarrow \mathrm{HFD}$ & $\downarrow H F D$ & $\begin{array}{l}\text { Lost the first-phase GSIS and } \\
\text { glucose intolerance on HFD }\end{array}$ \\
\hline $\begin{array}{l}\text { Mus- } \\
\text { GHRKO }\end{array}$ & Muscle cells & Mck & $?$ & $\begin{array}{l}\text { C57BL/ } \\
6 \times \mathrm{C} 3 \mathrm{H}\end{array}$ & $\downarrow$ & N.C. & N.C. & $\uparrow$ & $\uparrow$ & $\begin{array}{l}\text { Decreased systemic } \\
\text { inflammation, muscle and } \\
\text { hepatic triglyceride content (9) }\end{array}$ \\
\hline
\end{tabular}

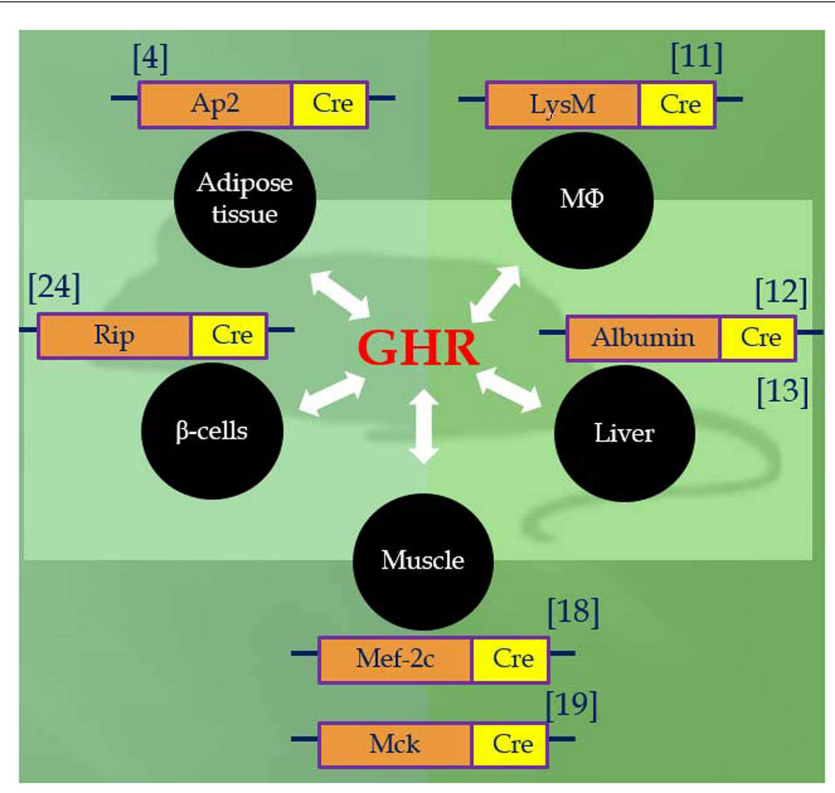

FIGURE 1 |Tissue-specific GHR knockouts using promoter Cre-loxP recombination.

these mutant mice are found to have preferential accumulation of subcutaneous fat depots, while visceral fat pads in animals with different genetic background are either less affected or diminished in size as compared to the control mice.

List et al. have recently disrupted GHR in white adipose tissue (WAT) under the aP2-cre promoter/enhancer and produced
Fat-GHRKO mice (10). Fat-GHRKO mice share some characteristics with whole-body GHRKO mice; they are obese with increased total body fat, enlarged adipocyte size, and increased circulating leptin levels (10). However, unlike global GHR null mice, these mice show no signs of metabolic improvements and have normal glucose homeostasis and normal/decreased levels of adiponectin (10). In interpreting these unexpected findings, it is necessary to consider that GHR was likely deleted not only in adipocyte but also in other cell types, including macrophages (11). Further studies using different Cre lines of mice, such as adiponectin-Cre transgenic mice, would be necessary to elucidate the direct role of $\mathrm{GH}$ in adipocytes from different depots. We would also add that much was learned about the role of insulin signaling in adipose tissue from studies in FIRKO mice, which were generated using the same aP2-cre Tg mice (12).

Infiltration into adipose tissue by macrophage $(M \Phi)$ has emerged as an important component in the pathogenesis of dietinduced obesity (DIO) and insulin resistance (13). The invading macrophages have been shown to be a major source of proinflammatory cytokines, such as IL- $1 \beta$ and TNF- $\alpha$ (14), and thus, are contributors to the establishment of the low-grade chronic inflammatory state associated with obesity. In order to understand the role of $\mathrm{GH}$ signaling in macrophage invasion, $\mathrm{M} \Phi$-specific $\mathrm{GH}$ receptor-KO (MacGHR-KO) mice were created in R. K. Menon's group by crossing LysMcre mice with GHR exon 4 floxed mice (15). Fed with a normal chow diet, MacGHR-KO exhibited normal growth profiles and metabolic characteristics (15). Compared to normal animals fed HFD, MacGHR-KO mice on the same diet had greater impairments of glucose tolerance and insulin sensitivity as revealed by insulin and glucose tolerance tests (15). Moreover, increased visceral WAT, enlarged adipocyte size, increased 
$M \Phi$ invasion, elevated proinflammatory cytokines, and attenuated insulin-stimulated Akt phosphorylation were detected in the WAT of HFD fed MacGHR-KO mice. These results suggest that $М \Phi-$ specific $\mathrm{GH}$ signaling plays an important role in the pathogenesis of DIO.

\section{HEPATIC GHR SIGNALING}

Hepatic GHRs have been shown to be expressed at high levels and therefore the liver is highly responsive to GH signaling. The liver is also the major site of IGF-I secretion and the main source of circulating IGF-I. Due to absence of negative feedback of serum IGF-I, LID mice have high circulating level of GH. The elevated GH secretion counteracts insulin action, decreasing insulin sensitivity, and glucose tolerance (5). These results are consistent with the ability of GH to affect various tissues via direct action, which might be independent of IGF-I. However, the precise contribution of $\mathrm{GH}$ action liver remains to be elucidated.

Using a similar approach, two independent groups have generated two lines of mice with liver-specific disruption of GHR (LivGHR-KO) under the albumin-cre driver $(6,7)$. Fan et al. reported that LivGHR-KO mice have normal body size and bone linear growth despite profound suppression of circulating IGFI level (6). Subsequently, List et al. found that Liv-GHRKO mice generated in Kopchick's group were smaller than littermate controls, with their body length and body weight significantly decreased in both sexes (7). In the first report (6), LivGHR$\mathrm{KO}$ mice showed the characteristics of metabolic abnormalities including hyperinsulinemia, impaired insulin signaling, abnormal glucose intolerance, hepatic steatosis, and altered lipid homeostasis. In contrast, in the second line of LivGHR-KO mice (7), all these metabolic parameters remained unaltered as compared to the controls except that fatty livers were manifested in male LivGHR-KO mice. The difference in genetic backgrounds and the diet employed in these two studies may account for the different phenotypes.

\section{GHR SIGNALING IN SKELETAL MUSCLE}

Growth hormone-IGF axis has a dramatic impact on skeletal muscle growth and anabolism. GH has been shown to stimulate cell mitosis, increase protein translation, promote satellite cell proliferation, and inhibit apoptosis $(16,17)$. There is also evidence that GH can affect muscle fiber composition (18). However, it will be important to distinguish between direct actions of GH and secondary IGF-I mediated GH effects. Using whole-body GHRKO mice, Sotiropoulos et al. found that GH enlarged skeletal muscle size by increasing myofiber size in the IGF-I independent manner (19). Interestingly, they have shown that GH had no impact on cell number, proliferation, or differentiation of the progenitor cells (19). These data indicate the importance of GH in skeletal muscle physiology via IGF-I independent mechanisms responsible for these effects.

The Clemens laboratory has recently characterized the novel line of skeletal muscle-specific GHR (MusGHR-KO) and IGFIR (MusIGFR-KO-1) knockout mice under myocyte-specific enhancer factor 2C (mef-2c-73k) promoter (8). In contrast with MusIGFR-KO mutant mice, MusGHR-KO-1 mice exhibited marked metabolic abnormalities including peripheral obesity, insulin resistance, and impaired glucose tolerance. Intriguingly, a second line of skeletal muscle-specific GHR knockout (MusGHRKO-2) mice developed by LeRoith's group [using muscle creatine kinase (MCK) promoter] were found to have the opposite metabolic phenotype (9). The MusGHR-KO-2 mice had reduced fat mass, improved metabolic markers when fed with normal diet, and were protected against metabolic impairments in the high-fatdiet settings. Taken together, these studies have indicated that that GHR signaling in different subsets of muscle cells could have different metabolic effects. There remain important areas for further investigation. Furthermore, in interpreting these findings using mef- $2 \mathrm{c}$ and MCK cre transgenic mice, it is necessary to consider that GHR was likely deleted not only in skeletal muscle cells but also in cardiac muscles.

\section{GHR SIGNALING DISRUPTION IN BETA CELLS}

The ability of pancreatic $\beta$-cells to synthesize and secrete insulin is the key to overcome the hyperglycemia and maintain the glucose homeostasis in the settings of insulin resistance. Impairment to secreting sufficient insulin levels in the face of hyperglycemia leads to the pathogenesis of diabetes (20). GH has been shown to play an important role in maintaining pancreatic $\beta$-cells mass (21), regulating $\beta$-cell proliferation (22), and differentiation (23) and stimulating gene expression of components in the insulin signaling pathway in these cells.

In order to elucidate the specific role of GH signaling pancreatic $\beta$-cells. Wu et al. generated $\beta$ cell-specific GHR null mice $(\beta \mathrm{GHRKO})$ employing RIP-Cre recombinase (24). $\beta$ GHRKO mice developed impaired glucose-stimulated insulin secretion (GSIS) while no alteration was revealed in GTT, ITT test, or $\beta$ cell staining. Intriguingly, when fed with HFD, $\beta$ GHRKO mice lost the first-phase GSIS and developed exacerbated glucose intolerance. These mutant mice exhibited a dramatic defect in $\beta$ cell hyperplasia due to decreased cell proliferation in response to HFD challenge. These data point out that $\mathrm{GH}$ signaling in $\beta$ cells is pivotal in the process of compensatory cell proliferation and insulin secretion in the state of the DIO.

\section{PERSPECTIVES}

There has been considerable recent progress in unraveling the effects and mechanisms of tissue-specific actions of GH signaling. However, many gaps remain in our understanding of these processes. For example, one future imperative will be to explore the $\mathrm{GH}$ action and signaling in tissues for which $\mathrm{GH}$ action has not been clearly evaluated. In particular, further study of key cell populations at the specific brain regions or in certain brain cell populations will be critical, with special attention to (1) hypothalamus, which is considered a key regulator of food intake and energy expenditure in mammals; (2) hippocampus, which is critical for learning and memory and is sensitive to hormonal fluctuations; and (3) glial cells including astrocytes, which have emerged as active players in CNS metabolic activities. It will be important to use these novel tissue/cell-specific GHR null mice to further dissect the functioning of the somatotropic axis, elucidate the mechanisms of cross-talk among different tissues, and determine the interactions between genes and environment in the context of development and aging. Such studies will offer critical insight into 
the basic physiological processes and molecular mechanisms that regulate metabolism and insulin action.

\section{ACKNOWLEDGMENTS}

Our studies and preparation of this article were supported by NIH grants P01 AG031736 (Andrzej Bartke), R01 AG019899 (Andrzej Bartke), and K01 AG048264 (Liou Y. Sun). The authors would like to thank Amanda Bekoin for help in manuscript preparation. We apologize to those whose work pertinent to this topic was not cited due to space and scope limitations or inadvertent omission.

\section{REFERENCES}

1. Bartke A, Sun LY, Longo V. Somatotropic signaling: trade-offs between growth, reproductive development, and longevity. Physiol Rev (2013) 93:571-98. doi:10. 1152/physrev.00006.2012

2. Zhou Y, Xu BC, Maheshwari HG, He L, Reed M, Lozykowski M, et al. A mammalian model for Laron syndrome produced by targeted disruption of the mouse growth hormone receptor/binding protein gene (the Laron mouse). Proc Natl Acad Sci U S A (1997) 94:13215-20. doi:10.1073/pnas.94.24.13215

3. List EO, Sackmann-Sala L, Berryman DE, Funk K, Kelder B, Gosney ES, et al. Endocrine parameters and phenotypes of the growth hormone receptor gene disrupted (GHR-/-) mouse. Endocr Rev (2011) 32:356-86. doi:10.1210/er.20100009

4. Yakar S, Liu JL, Stannard B, Butler A, Accili D, Sauer B, et al. Normal growth and development in the absence of hepatic insulin-like growth factor I. Proc Natl Acad Sci U S A (1999) 96:7324-9. doi:10.1073/pnas.96.13.7324

5. Yakar S, Liu JL, Fernandez AM, Wu Y, Schally AV, Frystyk J, et al. Liver-specific igf1 gene deletion leads to muscle insulin insensitivity. Diabetes (2001) 50:1110-8. doi:10.2337/diabetes.50.5.1110

6. Fan Y, Menon RK, Cohen P, Hwang D, Clemens T, DiGirolamo DJ, et al. Liver-specific deletion of the growth hormone receptor reveals essential role of growth hormone signaling in hepatic lipid metabolism. J Biol Chem (2009) 284:19937-44. doi:10.1074/jbc.M109.014308

7. List EO, Berryman DE, Funk K, Jara A, Kelder B, Wang F, et al. Liver-specific GH receptor gene-disrupted (LiGHRKO) mice have decreased endocrine IGF-I, increased local IGF-I, and altered body size, body composition, and adipokine profiles. Endocrinology (2014) 155:1793-805. doi:10.1210/en.2013-2086

8. Mavalli MD, DiGirolamo DJ, Fan Y, Riddle RC, Campbell KS, van Groen T, et al. Distinct growth hormone receptor signaling modes regulate skeletal muscle development and insulin sensitivity in mice. J Clin Invest (2010) 120:4007-20. doi:10.1172/JCI42447

9. Vijayakumar A, Wu Y, Sun H, Li X, Jeddy Z, Liu C, et al. Targeted loss of GHR signaling in mouse skeletal muscle protects against high-fat diet-induced metabolic deterioration. Diabetes (2012) 61:94-103. doi:10.2337/db11-0814

10. List EO, Berryman DE, Funk K, Gosney ES, Jara A, Kelder B, et al. The role of $\mathrm{GH}$ in adipose tissue: lessons from adipose-specific $\mathrm{GH}$ receptor gene-disrupted mice. Mol Endocrinol (2013) 27:524-35. doi:10.1210/me.2012-1330

11. Lee KY, Russell SJ, Ussar S, Boucher J, Vernochet C, Mori MA, et al. Lessons on conditional gene targeting in mouse adipose tissue. Diabetes (2013) 62:864-74. doi: $10.2337 / \mathrm{db} 12-1089$

12. Bluher M, Michael MD, Peroni OD, Ueki K, Carter N, Kahn BB, et al. Adipose tissue selective insulin receptor knockout protects against obesity and obesity-related glucose intolerance. Dev Cell (2002) 3:25-38. doi:10.1016/ S1534-5807(02)00199-5
13. Olefsky JM, Glass CK. Macrophages, inflammation, and insulin resistance. Annu Rev Physiol (2010) 72:219-46. doi:10.1146/annurev-physiol-021909-135846

14. Liang CP, Han S, Senokuchi T, Tall AR. The macrophage at the crossroads of insulin resistance and atherosclerosis. Circ Res (2007) 100:1546-55. doi:10.1161/CIRCRESAHA.107.152165

15. Lu C, Kumar PA, Sun J, Aggarwal A, Fan Y, Sperling MA, et al. Targeted deletion of growth hormone $(\mathrm{GH})$ receptor in macrophage reveals novel osteopontinmediated effects of $\mathrm{GH}$ on glucose homeostasis and insulin sensitivity in diet-induced obesity. J Biol Chem (2013) 288:15725-35. doi:10.1074/jbc.M113. 460212

16. Butler AA, Le Roith D. Control of growth by the somatropic axis: growth hormone and the insulin-like growth factors have related and independent roles. Annu Rev Physiol (2001) 63:141-64. doi:10.1146/annurev.physiol.63.1.141

17. Florini JR, Ewton DZ, Coolican SA. Growth hormone and the insulin-like growth factor system in myogenesis. Endocr Rev (1996) 17:481-517. doi:10. 1210/er.17.5.481

18. Klover P, Chen W, Zhu BM, Hennighausen L. Skeletal muscle growth and fiber composition in mice are regulated through the transcription factors STAT5a/b: linking growth hormone to the androgen receptor. FASEB J (2009) 23:3140-8. doi:10.1096/fj.08-128215

19. Sotiropoulos A, Ohanna M, Kedzia C, Menon RK, Kopchick JJ, Kelly PA, et al. Growth hormone promotes skeletal muscle cell fusion independent of insulinlike growth factor 1 up-regulation. Proc Natl Acad Sci U S A (2006) 103:7315-20. doi:10.1073/pnas.0510033103

20. Rudenski AS, Matthews DR, Levy JC, Turner RC. Understanding “insulin resistance": both glucose resistance and insulin resistance are required to model human diabetes. Metabolism (1991) 40:908-17. doi:10.1016/0026-0495(91) 90065-5

21. Nielsen JH, Galsgaard ED, Moldrup A, Friedrichsen BN, Billestrup N, Hansen JA, et al. Regulation of beta-cell mass by hormones and growth factors. Diabetes (2001) 1:S25-9. doi:10.2337/diabetes.50.2007.S25

22. Billestrup N, Nielsen JH. The stimulatory effect of growth hormone, prolactin, and placental lactogen on beta-cell proliferation is not mediated by insulin-like growth factor-I. Endocrinology (1991) 129:883-8. doi:10.1210/endo-129-2-883

23. Nielsen JH, Linde S, Welinder BS, Billestrup N, Madsen OD. Growth hormone is a growth factor for the differentiated pancreatic beta-cell. Mol Endocrinol (1989) 3:165-73. doi:10.1210/mend-3-1-165

24. Wu Y, Liu C, Sun H, Vijayakumar A, Giglou PR, Qiao R, et al. Growth hormone receptor regulates beta cell hyperplasia and glucose-stimulated insulin secretion in obese mice. J Clin Invest (2011) 121:2422-6. doi:10.1172/JCI45027

Conflict of Interest Statement: The authors declare that the research was conducted in the absence of any commercial or financial relationships that could be construed as a potential conflict of interest.

Received: 21 October 2014; paper pending published: 10 November 2014; accepted: 21 December 2014; published online: 19 January 2015.

Citation: Sun LY and Bartke A (2015) Tissue-specific GHR knockout mice: metabolic phenotypes. Front. Endocrinol. 5:243. doi: 10.3389/fendo.2014.00243

This article was submitted to Endocrinology of Aging, a section of the journal Frontiers in Endocrinology.

Copyright (C) 2015 Sun and Bartke. This is an open-access article distributed under the terms of the Creative Commons Attribution License (CC BY). The use, distribution or reproduction in other forums is permitted, provided the original author(s) or licensor are credited and that the original publication in this journal is cited, in accordance with accepted academic practice. No use, distribution or reproduction is permitted which does not comply with these terms. 